\title{
Temperature-controlled ionic liquid dispersive liquid phase microextraction combined with ultra-high-pressure liquid chromatography for the rapid determination of triclosan, triclocarban and methyl-triclosan in aqueous samples
}

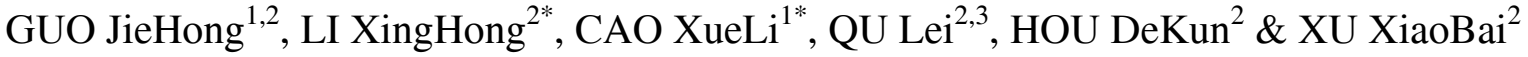 \\ ${ }^{1}$ School of Chemical and Environmental Engineering, Beijing Technology and Business University, Beijing 100048, China \\ ${ }^{2}$ State Key Laboratory of Environmental Chemistry and Eco-toxicology; Research Center of Eco-Environmental Sciences, \\ Chinese Academy of Sciences, Beijing 100085, China \\ ${ }^{3}$ Zhengzhou University, Zhengzhou 450001, China
}

Received March 11, 2010; accepted March 22, 2010; published online June 23, 2010

\begin{abstract}
As extraction solvents, ionic liquids have green characteristics. In this study, an environmentally benign analytical method termed temperature-controlled ionic liquid dispersive liquid phase microextraction (TIL-DLME) combined with ultra-highpressure liquid chromatography (UHPLC)-tunable ultraviolet detection (TUV) was developed for the pre-concentration and determination of triclosan (TCS), triclocarban (TCC) and methyl-triclosan (M-TCS) in water samples. Significant parameters that may affect extraction efficiencies were examined and optimized, including the types and amount of ionic liquids, volume of the diluent, heating temperature, cooling time, salt effect and $\mathrm{pH}$ value. Under the optimum conditions, linearity of the method was observed in the ranges of $0.0100-100 \mu \mathrm{g} \mathrm{L}-1$ for TCS and M-TCS, and $0.00500-50.0 \mu \mathrm{g} \mathrm{L}^{-1}$ for TCC with correlation coefficients $\left(r^{2}\right)>0.9903$. The limits of detection (LODs) ranged from 1.15 to $5.33 \mathrm{ng} \mathrm{L}^{-1}$. TCS in domestic water and TCC in reclaimed water were detected at the concentrations of 1.01 and $0.126 \mu \mathrm{g} \mathrm{L}^{-1}$, respectively. The spiked recoveries of the three target compounds in reclaimed water, irrigating water, waste water and domestic water samples were obtained in the ranges of $68.4 \%-71.9 \%, 61.6 \%-87.8 \%, 58.9 \%-74.9 \%$ and $64.9 \%-92.4 \%$, respectively. Compared with the previous dispersive liquid-liquid microextraction method (DLLME) about the determination of TCS, TCC and M-TCS, this method is not only more environmentally friendly but also more sensitive.
\end{abstract}

ionic liquid, temperature-controlled ionic liquid dispersive liquid phase microextraction, UHPLC, aqueous samples

\section{Introduction}

Room-temperature ionic liquids (RTILs) are a special class of ionic liquids (ILs) with the melting point at or below $25^{\circ} \mathrm{C}$ [1-3]. Contrary to conventional volatile organic compounds (VOCs), most ILs are generally regarded as "green" solvents due to their immensely low vapor pressure [4]. The class of imidazolium cation-based RTILs has been demon-

*Corresponding author (email: lxhzpb@rcees.ac.cn; caoxl@th.btbu.edu.cn) strated to be highly attractive in extraction and separation processes because their structural modifications in both the cation (especially the 1 and 3 positions of the imidazolium ring) and anion permit the tuning of properties such as miscibility with water and organic solvents, the melting point and viscosity [2]. Effort has been made with imidazolium ionic liquids as extraction solvents in liquid phase microextraction (LPME). LPME has been widely developed and studied $[5,6]$. There are three operation modes of LPME: headspace LPME (HS-LPME), direct-immersed LPME (DI-LPME) and hollow fiber LPME (HF-LPME) [5]. Liu et 
al. [1] have developed direct-immersed LPME (DI-LPME) with 1-octyl-3-methylimidazolium hexafluorophosphate $\left(\left[\mathrm{O}_{\text {mim }}\right] \mathrm{PF}_{6}\right)$ for the extraction of polycyclic aromatic hydrocarbons (PAHs). Vidal et al. [7] reported that 1-hexyl-3methylimidazolium hexafluorophosphate $\left(\left[\mathrm{H}_{\text {mim }}\right] \mathrm{PF}_{6}\right)$ hanging single droplet micro-extraction could provide sensitive determination of free benzophenone-3 in human urine samples prior to HPLC. RTILs based headspace single drop microextraction (HS-SDME) was also developed for the sensitive analysis of chlorobenzenes [8], trace DDT and its metabolites [9] with 1-butyl-3-methylimidazolium hexafluorophosphate $\left(\left[\mathrm{B}_{\mathrm{mim}}\right] \mathrm{PF}_{6}\right)$. Abulhassani et al. [10] optimized hollow fiber LPME (HF-LPME) with $\left[\mathrm{H}_{\text {mim }}\right] \mathrm{PF}_{6}$ to extract lead and nickel. However, these methods suffered drawbacks. Both DI-LPME and HS-LPME depend on a hanging drop, which was instable when the extraction is driven by a magnetic stir bar. Additionally, the small dimension of the suspending drop results in the difficulty of operation and low enrichment factors [6]. HF-LPME uses a hollow fiber to stabilize and protect the extraction solvent, but its small size of pores tends to be blocked. Zhou and Baghdadi $[3,11]$ developed temperature-controlled ionic liquid dispersive liquid phase microextraction (TIL-DLME) to overcome the aforementioned drawbacks. In the TIL-DLME, after the addition of IL, the samples are heated in a water bath to form a "homogeneous" solution, and the solution is subsequently cooled in ice-water for a certain time. The extraction is accomplished during the temperature rise and fall process [12]. Because solution is "homogeneous", target compounds in aqueous solution have far larger contact areas with the extraction solvent than those of the aforementioned models, resulting in the greater potential to achieve higher extraction efficiency and lower limits of detections (LODs). For example, for the extraction of PAHs, the enrichment factors (EFs) and LODs ranged from 18 to 53 and from 4 to $247 \mathrm{ng} \mathrm{L}^{-1}$ in the HS-DLME, respectively [13], while EFs ranged from 90 to 166 in the IL-based DI-LPME [1]. Whereas, in the TIL-DLME [14], much higher enrichment factors (313-337.2) and lower LODs (0.1-0.5 $\left.\mathrm{ng} \mathrm{L}^{-1}\right)$ were acquired. Some papers adopted ultrasound [15] and dispersive solvent [12] to break IL, but these methods do not present superior advantages over TIL-DLME. For the former, ultrasonic instruments could produce local overheating which may damage the examined chemicals and decrease extraction efficiencies. The latter has to apply more organic solvent as dispersive solvent, weakening the "green" function of IL. Though TIL-DLME adds the steps of heating and cooling with energy consumption, it significantly reduces the use of toxic and volatile organic solvents, and is a relatively "greener" extraction model.

Triclosan (5-chloro-2-(2,4-dichloro-phenoxy)-phenol, TCS [16]), triclocarban ( $N$-(4-chlorophenyl)- $N$-(3,4-dichlorophenyl) urea, TCC [16]) and methyl-triclosan (M-TCS, a metabolite of TCS [17]) are within a class of emerging pollutants in the environment and have attracted much attention [18-20]. Because TCS, TCC and M-TCS have high log octanol-water partition coefficient of 4.8, 4.9 and 5.2 [17], respectively, they are easy to transfer into the phase of IL from water and acquire higher enrichment factors. Guo et al. [21] have promoted a method of dispersive liquid-liquid microextraction (DLLME) to detect TCS, TCC and M-TCS. However, there exist inevitable defects in the developed method, including the consumption of volatile and toxic halogenated hydrocarbon as the extraction solvent, and the use of a third organic component as the dispersive solvent with higher LODs of target compounds (45.1 to $236 \mathrm{ng} \mathrm{L}^{-1}$ ). Based on the suitable properties of RTILs in liquid extraction, this study aims to develop an environmentally benign method to overcome the drawbacks of DLLME in the pretreatment of TCS, TCC and M-TCS in aqueous samples.

\section{Experimental}

\subsection{Materials and reagents}

Triclosan (purity, 99.5\%), triclocarban (purity, 99.5\%) and methyl-triclosan (purity, 99\%) were purchased from Dr. Ehrenstorfer (Augsburg, Germany). Ionic liquids 1-butyl-3methylimidazolium hexafluorophosphate $\left(\left[\mathrm{B}_{\text {mim }}\right] \mathrm{PF}_{6}\right.$, purity, 99\%), 1-hexyl-3-methylimidazolium hexafluorophosphate $\left(\left[\mathrm{H}_{\text {mim }}\right] \mathrm{PF}_{6}\right.$, purity, $\left.99 \%\right)$ and 1-octyl-3-methylimidazolium hexafluorophosphate $\left(\left[\mathrm{O}_{\text {mim }}\right] \mathrm{PF}_{6}\right.$, purity, $\left.99 \%\right)$ were purchased from Shanghai Cheng Jie Chemical Co., Ltd. (Shanghai, China). Acetonitrile (HPLC grade) and methanol (HPLC grade) were purchased from Tedia (Fairfield, OH, USA). Water was purified by a Milli-Q water purification system (Millipore, Bedford, MA, USA). Buffer solution (pH 9) was prepared as follows: $0.618 \mathrm{~g}$ boracic acid (Beijing Chemical Reagents Company, Beijing, China) was dissolved in $100 \mathrm{~mL} 0.1 \mathrm{~mol} \mathrm{~L}^{-1}$ potassium chloride (Sinopharm Chemical Reagent Co., Ltd., Shanghai, China) solution, and $42 \mathrm{~mL} 0.1 \mathrm{~mol} \mathrm{~L}^{-1}$ sodium hydroxide (Beijing Chemical Reagents Company, Beijing, China) solution was added. Before used as the mobile phase, the solution was diluted 20 times.

\subsection{Standard solution}

The individual stock solutions $\left(1.00 \mathrm{~g} \mathrm{~L}^{-1}\right)$ of TCS, TCC and M-TCS were prepared by dissolving the solid standard substance in methanol. Then, five levels of mixed standards (0.0100 $\mathrm{mg} \mathrm{L}^{-1} \mathrm{TCS}$ and M-TCS and $0.00500 \mathrm{mg} \mathrm{L}^{-1} \mathrm{TCC}$, $0.100 \mathrm{mg} \mathrm{L}^{-1} \mathrm{TCS}$ and M-TCS and $0.0500 \mathrm{mg} \mathrm{L}^{-1} \mathrm{TCC}$, $1.00 \mathrm{mg} \mathrm{L}^{-1} \mathrm{TCS}$ and M-TCS and $0.500 \mathrm{mg} \mathrm{L}^{-1} \mathrm{TCC}, 10.0$ $\mathrm{mg} \mathrm{L}^{-1}$ TCS and M-TCS and $5.00 \mathrm{mg} \mathrm{L}^{-1} \mathrm{TCC}, 100 \mathrm{mg} \mathrm{L}^{-1}$ TCS and M-TCS and $50.0 \mathrm{mg} \mathrm{L}^{-1}$ TCC) were prepared by mixing the individual stock solutions and diluting with methanol. 


\subsection{Instrumentation}

TCS, TCC and M-TCS were analyzed by an Aquity Ultra High Performance Liquid Chromatography system (UHPLC, Waters, Milford, MA, USA), composed of a binary solvent manager, a sample manager and a tunable UV detector. UHPLC analyses were performed on a bridged ethylene hybrid $(\mathrm{BEH}) \mathrm{C}_{18}$ analytical column $(50 \mathrm{~mm} \times 2.1 \mathrm{~mm}, 1.7$ $\mu \mathrm{m})$. Empower software was used for chromatographic data gathering and integration of chromatograms. A model CR22GII High-speed Refrigerated Centrifuge (Hitachi, Tokyo, Japan) was used for centrifugation and a supermixer (Melrose, Park, IL, USA) was applied to disperse the samples after the ionic liquid was injected into the aqueous samples and heated in the water bath.

\subsection{UHPLC conditions}

As shown in reference 21, the mobile phase consisted of buffer solution (A) and acetonitrile (B) with the gradient elution as follows: $50 \% \mathrm{~A} / 50 \% \mathrm{~B}$ with a flow rate of 0.4 $\mathrm{mL} \mathrm{min}^{-1}$ at $0 \mathrm{~min}, 40 \% \mathrm{~A} / 60 \% \mathrm{~B}$ with a flow rate of 0.5 $\mathrm{mL} \mathrm{min}^{-1}$ at $1.0 \mathrm{~min}$ (Waters curve type 6), and reconditioning the column with $50 \% \mathrm{~A} / 50 \% \mathrm{~B}$ after washing the column with $90 \% \mathrm{~B}$ at the rate of $0.3 \mathrm{~mL} \mathrm{~min}^{-1}$ for $1.5 \mathrm{~min}$. The total running time for the analysis was $5 \mathrm{~min}$. The peaks were detected at the wavelength of $283 \mathrm{~nm}$ with TUV. $25^{\circ} \mathrm{C}$ and $30{ }^{\circ} \mathrm{C}$ were adopted as the sample and column temperature, respectively. The injection volume was $5.0 \mu \mathrm{L}$.

\subsection{TIL-DLME procedure}

For this extraction procedure, $0.058 \mathrm{~g}\left[\mathrm{O}_{\mathrm{mim}}\right] \mathrm{PF}_{6}$ was placed into a $10 \mathrm{~mL}$ glass test tube with a conical bottom which contained $5 \mathrm{~mL}$ water. The conical tube was heated in a water bath at $90{ }^{\circ} \mathrm{C}$. Under this temperature, the IL was dissolved completely and mixed entirely with the solution, becoming one phase especially after vortexing with a mixer. The tube was thereafter immediately put into $0{ }^{\circ} \mathrm{C}$ ice-water mixture and cooled for $40 \mathrm{~min}$. A cloudy and turbid solution was formed which was then centrifuged for $5 \mathrm{~min}$ at 3000 rpm. Then, two distinct phases were found and the upper aqueous phase was removed with a syringe while the sedimented phase was diluted with methanol to $100 \mu \mathrm{L}, 5.0 \mu \mathrm{L}$ of which was finally injected automatically for UHPLC analysis.

\section{Results and discussion}

\subsection{Optimization of TIL-DLME}

Temperature-controlled ionic liquid dispersive liquid-phase microextraction is a new process, but it has similarities with the developed LPME. In order to obtain maximum extraction efficiency, significant experimental factors that would influence the enrichment performance were investigated and discussed in detail in the following sections, including the types and amount of ionic liquids, volume of diluting methanol, extraction time, salt effect and $\mathrm{pH}$ value. Extraction recovery was used to assess the optimized parameters as described by Guo et al. [21] and Li et al. [22]. The spiked concentrations of compounds in the water samples were 100 $\mu \mathrm{g} \mathrm{L}^{-1}$ for TCS and M-TCS, and $50.0 \mu \mathrm{g} \mathrm{L}^{-1}$ for TCC.

\subsubsection{Selection of ionic liquids}

In TIL-DLME, some factors need to be considered when ILs are selected. ILs are required to be water-immiscible, liquid and inexpensive [11]. Imidazolium-ILs containing $\mathrm{PF}_{6}^{-}$are hydrophobic, relatively inexpensive and liquid in the experimental conditions. Therefore, $\left[\mathrm{B}_{\mathrm{mim}}\right] \mathrm{PF}_{6}$ (solubility in $100 \mathrm{~mL}$ water, $1.88 \mathrm{~g}, 25^{\circ} \mathrm{C}$ ), $\left[\mathrm{H}_{\text {mim }}\right] \mathrm{PF}_{6}$ (solubility in $100 \mathrm{~mL}$ water, $0.75 \mathrm{~g}, 25^{\circ} \mathrm{C}$ ) and $\left[\mathrm{O}_{\text {mim }}\right] \mathrm{PF}_{6}$ (solubility in $100 \mathrm{~mL}$ water, $0.20 \mathrm{~g}, 25{ }^{\circ} \mathrm{C}$ ) were selected and compared [1]. Each solvent was evaluated through comparing the extraction recoveries of these compounds in the operating conditions with $5.00 \mathrm{~mL}$ water samples, $0.094 \mathrm{~g}$ ILs, the heating temperature of $90{ }^{\circ} \mathrm{C}$, cooling time of $5 \mathrm{~min}$ and centrifugation under $3000 \mathrm{rpm}$ for $5 \mathrm{~min}$ at $4{ }^{\circ} \mathrm{C}$. After injection to the UHPLC-TUV, it was found that in the chromatograms, the peak of $\left[\mathrm{B}_{\text {mim }}\right] \mathrm{PF}_{6}$ partly overlaps with that of TCC, and the peak of $\left[\mathrm{H}_{\text {mim }}\right] \mathrm{PF}_{6}$ partly overlaps with that of TCS, which made quantification of TCC and TCS inaccurate. As for $\left[\mathrm{O}_{\mathrm{mim}}\right] \mathrm{PF}_{6}$, it had no apparent interruption with the peaks of target compounds. Higher volume of sedimented phase was obtained while extracting with $\left[\mathrm{O}_{\text {mim }}\right] \mathrm{PF}_{6}$ because the solubility of $\left[\mathrm{O}_{\text {mim }}\right] \mathrm{PF}_{6}$ is lower than that of $\left[\mathrm{B}_{\text {mim }}\right] \mathrm{PF}_{6}$ and $\left[\mathrm{H}_{\text {mim }}\right] \mathrm{PF}_{6}$. For the aforementioned reasons, $\left[\mathrm{O}_{\text {mim }}\right] \mathrm{PF}_{6}$ was selected as the extraction ionic liquid.

\subsubsection{The choice of the amount of [Omim]PF 6 and the volume of the diluent}

The amount of the extraction solvent is a significant factor influencing the extraction recoveries of target compounds. In this study, $0.0340 \mathrm{~g}, 0.0450 \mathrm{~g}, 0.0580 \mathrm{~g}, 0.0770 \mathrm{~g}$ and $0.0940 \mathrm{~g}$ of $\left[\mathrm{O}_{\mathrm{mim}}\right] \mathrm{PF}_{6}$ were investigated with other conditions mentioned previously maintained constant. Figure 1 shows that the recoveries are best when the weight of $\left[\mathrm{O}_{\text {mim }}\right] \mathrm{PF}_{6}$ is $0.0580 \mathrm{~g}$ and unfavorable in other conditions. When the amount was lower than $0.0580 \mathrm{~g}$, the extraction capacity was limited. When the amount was higher than $0.0580 \mathrm{~g}$, the extraction process probably reached equilibrium and no more target compounds could be extracted into the IL phase. The limited dilution solvent (about $100 \mu \mathrm{L}$ methanol) before injection may fail to completely dissolve the large sediment phase, rendering the recoveries low.

As ionic liquid is sticky and hard to be withdrawn with a syringe, methanol was used in this study as the diluent to dissolve the sedimented phase, added after water was removed from the test tube. To test the effect of the dissolving capacity of methanol to $\mathrm{IL}\left[\mathrm{O}_{\text {mim }}\right] \mathrm{PF}_{6}$ on the recoveries of 


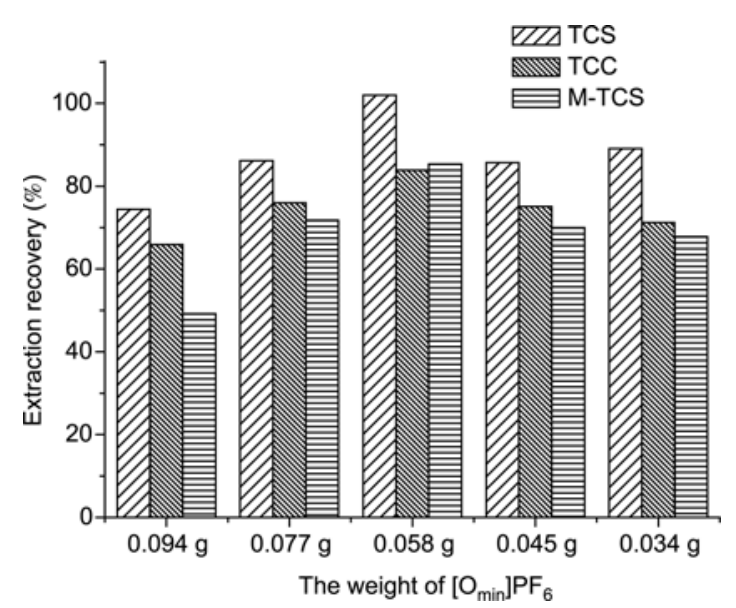

Figure 1 Effect of the weight of $\left[\mathrm{O}_{\min }\right] \mathrm{PF}_{6}$ on the recoveries of TCS, TCC and M-TCS obtained from TIL-DLME. Extraction conditions: water sample volume, $5.00 \mathrm{~mL}$; heating temperature, $90{ }^{\circ} \mathrm{C}$; extraction time, 5 min; concentrations of each compound, $100 \mu \mathrm{g} \mathrm{L}{ }^{-1}$ for TCS and M-TCS, and $50.0 \mu \mathrm{g} \mathrm{L}^{-1}$ for TCC.

target compounds, 30, 50, 100, 150 and $200 \mu \mathrm{L}$ methanol were discussed and compared when $0.0580 \mathrm{~g}\left[\mathrm{O}_{\mathrm{mim}}\right] \mathrm{PF}_{6}$ was employed. The curve of the recoveries of target compounds versus different volumes of methanol in Figure 2 suggests that the recoveries increase as methanol adds from $30 \mu \mathrm{L}$ to $100 \mu \mathrm{L}$ and keeps constant in the range of 100-200 $\mu \mathrm{L}$. Because a small volume $(<100 \mu \mathrm{L})$ of the diluent (methanol) could not completely dissolve the obtained sedimented phase, absolute amount of pollutants would decrease in per unit volume, resulting in low recoveries. When methanol was large enough, the compounds could be fully distributed in the diluent and high recoveries were responded. However, more methanol $(>100 \mu \mathrm{L})$ is not better after IL has been completely dissolved, because the determined concentrations in the instrument would decrease with the increase of

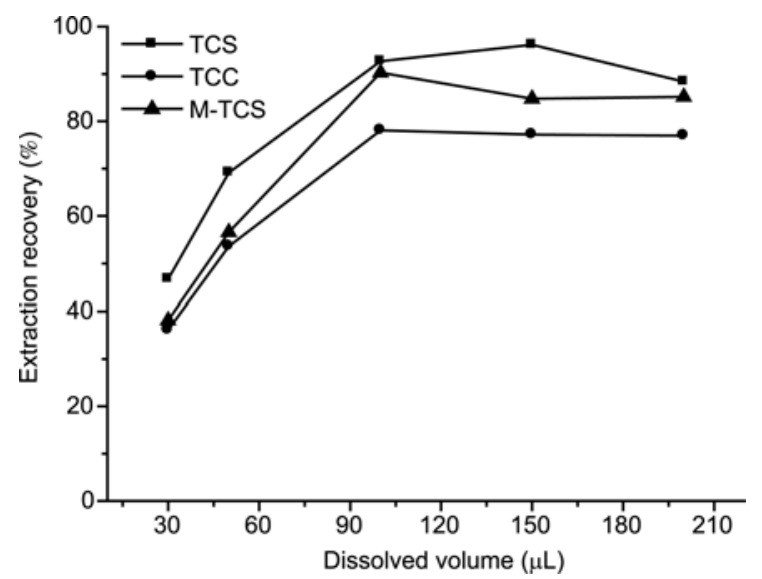

Figure 2 Effect of the volume of methanol on the recoveries of TCS, TCC and M-TCS obtained from TIL-DLME. Extraction conditions: water sample volume, $5.00 \mathrm{~mL}$; heating temperature, $90{ }^{\circ} \mathrm{C}$; extraction time, 40 min; ionic liquid, $0.058 \mathrm{~g}\left[\mathrm{O}_{\text {min }}\right] \mathrm{PF}_{6}$; concentrations of each compound, $100 \mu \mathrm{g} \mathrm{L}^{-1}$ for TCS and M-TCS, and $50.0 \mu \mathrm{g} \mathrm{L}{ }^{-1}$ for TCC. methanol, ultimately increasing the LODs of the entire method. Though larger volume of methanol could completely dissolve larger amount of $\left[\mathrm{O}_{\text {mim }}\right] \mathrm{PF}_{6}$, the recoveries could not get better than the condition using $100 \mu \mathrm{L}$ methanol to dissolve $0.058 \mathrm{~g}\left[\mathrm{O}_{\mathrm{mim}}\right] \mathrm{PF}_{6}$. Thus, for the purpose to obtain good recovery and high sensitivity, $100 \mu \mathrm{L}$ methanol was employed to dissolve $0.0580 \mathrm{~g}\left[\mathrm{O}_{\mathrm{mim}}\right] \mathrm{PF}_{6}$ in the following experiments.

\subsubsection{Effect of the heating temperature and cooling time}

ILs could be dissolved in water at certain temperatures and precipitate at low temperatures. For this reason, this study selected different temperatures to disperse IL for the formation of fine droplets in the cooling step. As the solubility of $\left[\mathrm{O}_{\text {mim }}\right] \mathrm{PF}_{6}$ changes with temperature, the heating temperature ranging from 40 to $100{ }^{\circ} \mathrm{C}$ in the water bath was adopted to test the effect, in which the analytes could keep the chemical structure stable. As shown in Figure 3, the recoveries of target compounds increased from 57.6\%$63.4 \%$ at $40{ }^{\circ} \mathrm{C}$ to $70.7-97.8 \%$ at $90{ }^{\circ} \mathrm{C}$, ascending with the temperature. Whereas, when the water bath was set at $100{ }^{\circ} \mathrm{C}$, the recoveries decreased instead. At low temperatures, the solubility of $\left[\mathrm{O}_{\mathrm{mim}}\right] \mathrm{PF}_{6}$ is relatively low and it failed to disperse completely, which limited the effective utilization of all added IL and the diffused rate of the analytes, resulting in a relatively small amount of analytes migrating into the IL phase. However, at $100{ }^{\circ} \mathrm{C}$ analytes probably volatilized with water vapour. Therefore, $90{ }^{\circ} \mathrm{C}$ water bath was applied to heat the ionic liquid.

After heated and mixed completely, the water samples were immediately placed into an ice-water bath and kept for a certain time, then taken out and ready to be centrifuged. The time interval was named as the cooling time which plays a significant role in the method. Through sudden cooling, a large amount of IL would precipitate and extraction

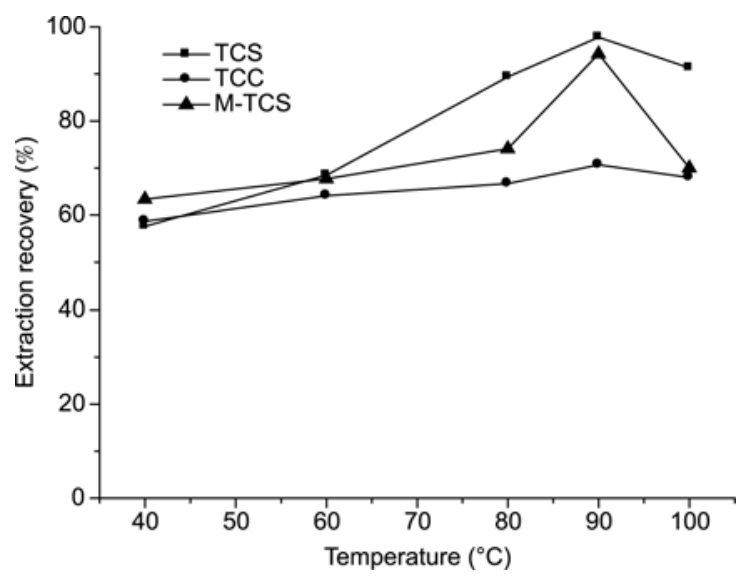

Figure 3 Effect of temperature on the recoveries of TCS, TCC and M-TCS obtained from TIL-DLME. Extraction conditions: water sample volume, $5.00 \mathrm{~mL}$; ionic liquid: $0.058 \mathrm{~g}\left[\mathrm{O}_{\mathrm{min}}\right] \mathrm{PF}_{6}$; extraction time: $5 \mathrm{~min}$; concentrations of each compound: $100 \mu \mathrm{g} \mathrm{L}^{-1}$ for TCS and M-TCS, and $50.0 \mu \mathrm{g} \mathrm{L}^{-1}$ for TCC. 
could be completed in a short time. It was generally supposed that extract recoveries may increase and reach a constant as the cooling time lasts. Accordingly, a series of experiments were employed to find out the optimum point. In Figure 4 , good extraction recoveries $(>70 \%)$ were found in the whole tested period, but best extraction recoveries were observed at the time period of $40 \mathrm{~min}$ and differed little as the time increased from $40 \mathrm{~min}$ to $120 \mathrm{~min}$. When the time was short (<40 min), ionic liquid could not completely dissolve and part of the target compounds failed to be acquired. As a result, to attain more sedimented phase and higher extraction recoveries, $40 \mathrm{~min}$ was selected as extraction time before samples were centrifuged.

\subsubsection{Salt effect}

In most sample pretreatment techniques, the addition of salt often increases the extraction performance due to salting out effect [23]. In our study, the effect of sodium chloride $(\mathrm{NaCl})$ with the percentages of $0 \%, 2.0 \%, 5.0 \%, 10.0 \%$ and $20.0 \%$ $(w / v)$ was investigated. The plot of extraction recovery versus ionic strength is shown in Figure 5, which clearly indicates that the extraction recoveries of target compounds changes little in the range of $0 \%-2 \%$ and decreases gradually as the concentration of $\mathrm{NaCl}$ increases from $2 \%$ to $20 \%$. This phenomenon may be explained by the fact that electrostatic interactions between polar compounds and salt ions increase, which reduces the capacity of target compounds to move into the extract phase, and leads to the occurrence of low recoveries [24]. Because the addition of $\mathrm{NaCl}$ could not enhance the extraction efficiency, the salt addition step was not adopted for further study.

\subsubsection{Choice of the $\mathrm{pH}$ value}

In the extraction procedure of organic pollutants in environmental water samples, $\mathrm{pH}$ is usually one of the significant factors because the $\mathrm{pH}$ value of a solution determines

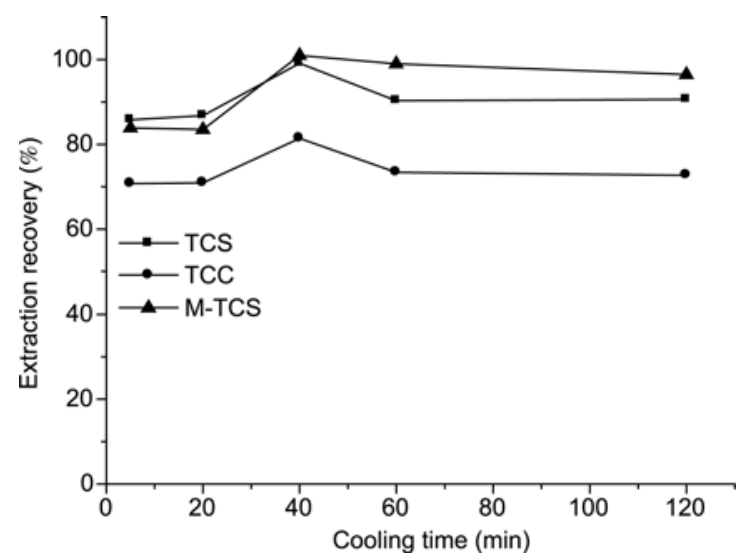

Figure 4 Effect of cooling time on the recoveries of TCS, TCC and M-TCS obtained from TIL-DLME. Extraction conditions: water sample volume, $5.00 \mathrm{~mL}$; heating temperature, $90{ }^{\circ} \mathrm{C}$; ionic liquid: $0.058 \mathrm{~g}$ $\left[\mathrm{O}_{\text {min }}\right] \mathrm{PF}_{6}$; concentrations of each compound: $100 \mu \mathrm{g} \mathrm{L}^{-1}$ for TCS and M-TCS, and $50.0 \mu \mathrm{g} \mathrm{L}^{-1}$ for TCC.



Figure 5 Effect of salt addition on the recoveries of TCS, TCC and M-TCS obtained from TIL-DLME. Extraction conditions: water sample volume, $5.00 \mathrm{~mL}$; heating temperature, $90{ }^{\circ} \mathrm{C}$; extraction time: $40 \mathrm{~min}$; ionic liquid: $0.058 \mathrm{~g}\left[\mathrm{O}_{\mathrm{min}}\right] \mathrm{PF}_{6}$; concentrations of each compound: $100 \mu \mathrm{g}$ $\mathrm{L}^{-1}$ for TCS and M-TCS, and $50.0 \mu \mathrm{g} \mathrm{L}^{-1}$ for TCC.

the existing state of analytes. To examine the effect of $\mathrm{pH}$, concentrated hydrochloric acid $(\mathrm{HCl})$ was used to regulate acidity while sodium hydroxide $(\mathrm{NaOH})$ was added to adjust alkalinity. On account of the stability of analytes and the tolerance of the column equipped in UHPLC, the range of $\mathrm{pH} 3-11$ was examined. The results in Figure 6 indicate that the extraction efficiencies of the three compounds maintain higher than $60 \%$ under acid and neutral conditions. The recoveries of TCC and M-TCS increased as the increase of alkalinity. However, when the alkalinity ascended to $\mathrm{pH} 11$, the recovery of TCS decreased. The phenomena may be explained by the structure characteristics of the compounds [21]. TCS predominates the phenolate form and could be rapidly photo-degraded in the presence of sunlight under alkaline conditions of $\mathrm{pH}>8$ in water [25]. For TCC and TCS, their ionized forms gradually changed to molecule forms when the $\mathrm{pH}$ value increased, which are readily extracted to ionic liquid phase. Based on the reasons mentioned above, neutrality was selected as the extraction condition in

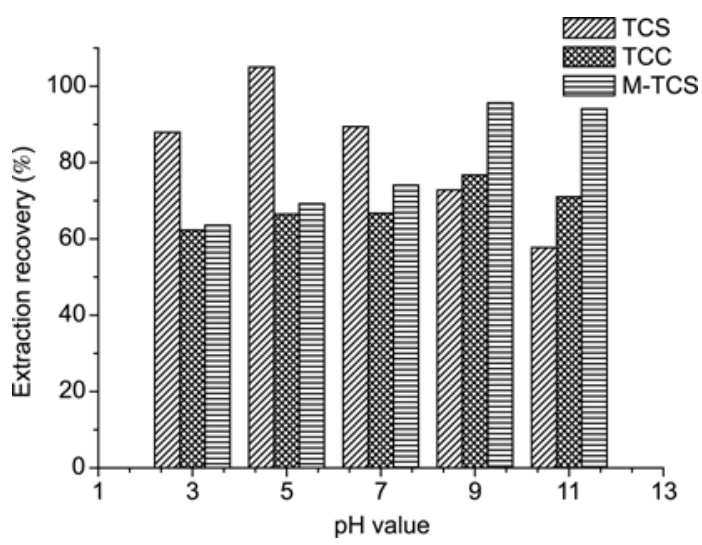

Figure 6 Effect of the $\mathrm{pH}$ value on the recoveries of TCS, TCC and M-TCS obtained from TIL-DLME. Extraction conditions are shown in Figure 5 . 
our experiment.

\subsection{Evaluation of method performance}

\subsubsection{Main method parameters}

The corresponding parameters for these analytes with TILDLME-UHPLC method were tested using spiked water samples under the optimum conditions as described above. Calibration curves were made at five different concentration levels and good linearity was yielded (Table 1). The linearity was observed in the ranges of $0.0100-100 \mu \mathrm{g} \mathrm{L}^{-1}$ for TCS, 0.00500-50.0 $\mu \mathrm{g} \mathrm{L}^{-1}$ for TCC and 0.0100-100 $\mu \mathrm{g} \mathrm{L}^{-1}$ for M-TCS. The correlation coefficients $\left(r^{2}\right)$ of this method ranged from $0.9905,0.9979$ to 0.9903 and the standard error (SD) of the regression lines of TCS, TCS and M-TCS were 1031.44, 511.05 and 624.73, respectively. The limits of detection (LODs), based on signal-to-noise ratio $(\mathrm{S} / \mathrm{N})$ of 3 , were $1.15,1.46$ and $5.33 \mathrm{ng} \mathrm{L}^{-1}$ for TCS, TCC and M-TCS, respectively. The relative standard deviations varied from $8.60 \%, 7.1 \%$ to $4.30 \%$ and the enrichment factors ranged from 110 to 141 at the level of $100 \mu \mathrm{g} \mathrm{L}^{-1}$ for TCS and M-TCS, and $50.0 \mu \mathrm{g} \mathrm{L}^{-1}$ for TCC $(n=5)$. The linear ranges of TIL-DLME are wider than the ranges of DLLME in reference 21 which are $0.0500-100 \mu \mathrm{g} \mathrm{L}^{-1}$ for TCS, 0.0250$50.0 \mu \mathrm{g} \mathrm{L}^{-1}$ for TCC and $0.500-100 \mu \mathrm{g} \mathrm{L}^{-1}$ for M-TCS. LODs of TIL-DLME are lower than the range of 42.1-236 $n g \mathrm{~L}^{-1}$ in DLLME.

\subsubsection{Real water sample analysis}

For real environmental sample determination, several water samples including irrigating water, reclaimed water, waste water and domestic water were selected for the determination of the three target compounds. Irrigating water was sampled from the Research Center for Eco-Environment Sciences, Chinese Academy of Sciences, Beijing, China. Waste water and reclaimed water were sampled from the waste water treatment plant of Beijing Technology and Business University, Beijing, China. Domestic water was sampled from the drainage in our lab after gargling with mouthwash. All samples were filtered through $0.22 \mu \mathrm{m}$ filter membrane and stored at $4{ }^{\circ} \mathrm{C}$ before use. As a result, TCS and TCC were detected with concentrations of $1.01 \mu \mathrm{g}$ $\mathrm{L}^{-1}$ in domestic water and $0.126 \mu \mathrm{g} \mathrm{L}^{-1}$ in reclaimed water (see Figure 7 and Table 2), respectively. The LODs for domestic water and reclaimed water were calculated in the ranges of $15.4-88.4 \mathrm{ng} \mathrm{L}^{-1}$ and $4.68-97.4 \mathrm{ng} \mathrm{L}^{-1}$, respectively. To evaluate real water effect, four types of real water samples were spiked with the mixture of $10.0 \mu \mathrm{g} \mathrm{L}^{-1} \mathrm{TCS}$ and M-TCS, and $5.00 \mu \mathrm{g} \mathrm{L}^{-1}$ TCC. As shown in Table 2, the spiked recoveries and relative standard deviations (RSD) are in the ranges of $58.9-92.4 \%$ and $1.12-20.0 \%$, respectively. The amounts of analytes extracted by TIL-DLME

Table 1 Main method parameters of TIL-DLME ${ }^{\text {a) }}$

\begin{tabular}{ccccc}
\hline Compounds & Linear range $\left(\mu \mathrm{g} \mathrm{L}^{-1}\right)$ & Standard error & $r^{2}$ & $\left.\mathrm{LOD}^{2}(\mu \mathrm{g} \mathrm{L})^{-1}\right)$ \\
\hline TCS & $0.01-100$ & 1031.44 & 0.9905 & 0.00115 \\
TCC & $0.005-50$ & 511.05 & 0.9979 & 0.00146 \\
M-TCS & $0.01-100$ & 624.73 & 0.9903 & 4.3 \\
\hline
\end{tabular}

Extraction conditions: water sample volume, $5.00 \mathrm{~mL}$; heating temperature, $90{ }^{\circ} \mathrm{C}$; extraction time, $40 \mathrm{~min}$; ionic liquid, $0.058 \mathrm{~g}\left[\mathrm{O}_{\text {min }}\right] \mathrm{PF}_{6}$.

Table 2 Amounts of TCC, TCS and M-TCS detected originally, spiked recovery (\%) and relative standard deviations (RSD, \%) in real aqueous samples ${ }^{\text {a) }}$

\begin{tabular}{|c|c|c|c|c|}
\hline & & TCS & TCC & M-TCS \\
\hline \multirow{3}{*}{ Reclaimed water $^{\mathrm{c})}(n=3)$} & found $\left(\mu \mathrm{g} \mathrm{L}^{-1}\right)$ & $\mathrm{ND}^{\mathrm{b})}$ & 0.126 & ND \\
\hline & recovery $(\%)$ & 68.4 & 71.2 & 71.9 \\
\hline & RSD (\%) & 10.4 & 9.5 & 20 \\
\hline \multirow{3}{*}{ Irrigating water $(n=3)$} & found $\left(\mu \mathrm{g} \mathrm{L}^{-1}\right)$ & ND & ND & ND \\
\hline & recovery $(\%)$ & 87.8 & 61.6 & 66.4 \\
\hline & $\operatorname{RSD}(\%)$ & 6.84 & 10.5 & 5.64 \\
\hline \multirow{3}{*}{ Waste water $(n=3)$} & found $\left(\mu \mathrm{gL}^{-1}\right)$ & ND & ND & ND \\
\hline & recovery $(\%)$ & 74.9 & 58.9 & 67.3 \\
\hline & $\operatorname{RSD}(\%)$ & 15.6 & 14.3 & 16.6 \\
\hline \multirow{3}{*}{ Domestic water $^{\mathrm{d})}(n=3)$} & found $\left(\mu \mathrm{g} \mathrm{L}^{-1}\right)$ & 1.01 & ND & ND \\
\hline & recovery $(\%)$ & 92.4 & 83.7 & 64.9 \\
\hline & $\operatorname{RSD}(\%)$ & 1.17 & 1.12 & 6.4 \\
\hline
\end{tabular}

a) Extraction conditions: water sample volume, $5.00 \mathrm{~mL}$; heating temperature, $90{ }^{\circ} \mathrm{C}$; extraction time, $40 \mathrm{~min}$; ionic liquid, $0.058 \mathrm{~g}\left[\mathrm{O}_{\text {min }}\right] \mathrm{PF}$; added amounts of TCS, TCC and M-TCS were $10.0 \mu \mathrm{g} \mathrm{L}^{-1}, 5.00 \mu \mathrm{g} \mathrm{L}^{-1}$ and $10.0 \mu \mathrm{g} \mathrm{L}^{-1}$, respectively; b) not detected; c) LODs of TCS, TCC and M-TCS in reclaimed water were $0.318,0.0468$ and $0.974 \mu \mathrm{g} \mathrm{L}^{-1}$, respectively; d) LODs of TCS, TCC and M-TCS in domestic water were $0.330,0.154$ and $0.884 \mu \mathrm{g} \mathrm{L}^{-1}$, respectively. 

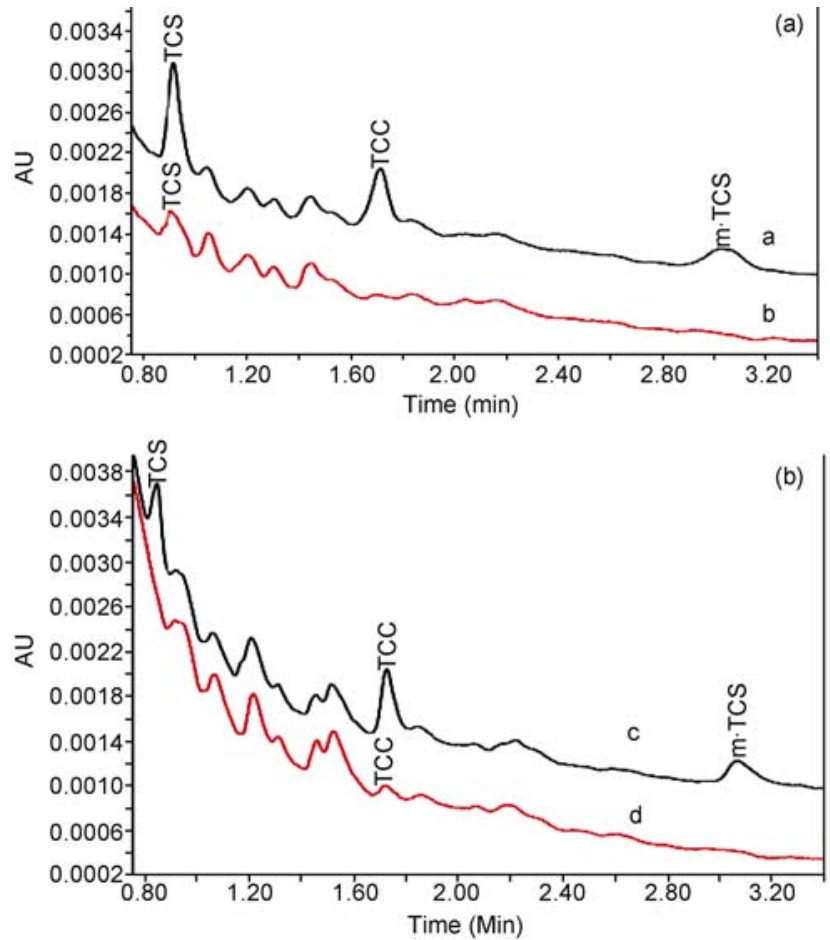

Figure 7 Chromatograms of blank domestic water and spiked domestic water (a) and chromatograms of the blank reclaimed water and spiked reclaimed water (b) with the spiked samples at concentration levels of 10.0 $\mu \mathrm{g} \mathrm{L}^{-1}$ for TCS and M-TCS and $5.00 \mu \mathrm{g} \mathrm{L}^{-1}$ for TCC obtained using TIL-DLME combined with UHPLC-TUV. Extraction conditions are shown in Figure 5. a, c: spiked samples; b, d: blank samples.

accord well with the known values spiked in environmental matrices. The good linearity and satisfactory recoveries show that TIL-DLME with UHPLC-TUV is feasible for the determination of TCS, TCC and M-TCS in aqueous samples.

\section{Conclusions}

In this study, the method of TIL-DLME-UHPLC-TUV has been developed to determine the trace amounts of TCS, TCC and M-TCS in aqueous samples. Compared with DLLME, TIL-DLME shows wider linearity, lower LODs, more economic availability and environmental friendliness with less consumption of toxic organic solvents. The proposed method is more practical when applied to the preconcentration and rapid determination of TCS, TCC and M-TCS in aqueous samples.

The authors express their great thanks for the support from the National High Technology Research and Development Program of China (122007AA061601) and the National Natural Science Foundation of China and the National Basic Research Program of China (20607026, 20877092 \& 20877005).

1 Liu JF, Jiang GB, Chi YG, Cai YQ, Zhou QX, Hu JT. Use of ionic liquids for liquid-phase microextraction of polycyclic aromatic hydrocarbons. Anal Chem, 2003, 75: 5870-5876

2 Schrekker HS, Stracke MP, Schrekker CML, Dupont J. Etherfunctionalized imidazolium hexafluorophosphate ionic liquids for improved water miscibilities. Ind Eng Chem Res, 2007, 46: 7389-7392

3 Zhou QX, Bai HH, Xie GH, Xiao JP. Trace determination of organophosphorus pesticides in environmental samples by temperaturecontrolled ionic liquid dispersive liquid-phase microextraction. $J$ Chromatogr A, 2008, 1188: 148-153

4 Kulkarni PS, Branco LC, Crespo JG, Afonso CAM. Capture of dioxins by ionic liquids. Environ Sci Technol, 2008, 42: 2570-2574

5 Xiong $\mathrm{J}, \mathrm{Hu}$ B. Comparison of hollow fiber liquid phase microextraction and dispersive liquid-liquid microextraction for the determination of organosulfur pesticides in environmental and beverage samples by gas chromatography with flame photometric detection. J Chromatogr A, 2008, 1193: 7-18

6 Bai HH, Zhou QX, Xie GH, Xiao JP. Enrichment and sensitive determination of dichlorodiphenyltrichloroethane and its metabolites with temperature controlled ionic liquid dispersive liquid phase microextraction prior to high performance liquid phase chromatography. Anal Chim Acta, 2009, 651: 64-68

7 Vidal L, Chisvert A, Canals A, Salvador A. Sensitive determination of free benzophenone-3 in human urine samples based on an ionic liquid as extractant phase in single-drop microextraction prior to liquid chromatography analysis. J Chromatogr A, 2007, 1174: 95-103

8 Vidal L, Psillakis E, Domini CE, Grané N, Marken F, Canals A. An ionic liquid as a solvent for headspace single drop microextraction of chlorobenzenes from water samples. Anal Chim Acta, 2007, 584: 189-195

9 Ye CL, Zhou QX, Wang XM, Headspace liquid-phase microextraction using ionic liquid as extractant for the preconcentration of dichlorodiphenyltrichloroethane and its metabolites at trace levels in water samples. Anal Chim Acta, 2006, 572: 165-171

10 Abulhassani J, Manzoori JL, Amjadi M. Hollow fiber based-liquid phase microextraction using ionic liquid solvent for preconcentration of lead and nickel from environmental and biological samples prior to determination by electrothermal atomic absorption spectrometry. $J$ Hazard Mater, 2009, 176: 481-486

11 Baghdadi M, Shemirani F. Cold-induced aggregation microextraction: A novel sample preparation technique based on ionic liquids. Anal Chim Acta, 2008, 613: 56-63

12 Liu Y, Zhao EC, Zhu WT, Gao HX, Zhou ZQ. Determination of four heterocyclic insecticides by ionic liquid dispersive liquid-liquid microextraction in water samples. J Chromatogr A, 2009, 1216: 885-891

13 Pena MT, Casais MC, Mejuto MC, Cela R. Development of an ionic liquid based dispersive liquid-liquid microextraction method for the analysis of polycyclic aromatic hydrocarbons in water samples. $J$ Chromatogr A, 2009, 1216: 6356-6364

$14 \mathrm{Wu}$ YL, Xia LB, Chen R, Hu B. Headspace single drop microextraction combined with HPLC for the determination of trace polycyclic aromatic hydrocarbons in environmental samples. Talanta, 2008, 74: 470-477

15 Li SQ, Cai S, Hu W, Chen H, Liu HL. Spectrochim Acta, Part B, 2009, 64: 666-671

16 Panagiotou AN, Sakkas VA, Albanis TA. Application of chemometric assisted dispersive liquid-liquid microextraction to the determination of personal care products in natural waters. Anal Chim Acta, 2009, 649: $135-140$

17 Coogan MA, Edziyie RE, La Point TW, Venables BJ. Algal bioaccumulation of triclocarban, triclosan, and methyl-triclosan in a North Texas wastewater treatment plant receiving stream. Chemosphere, 2007, 67: 1911-1918

18 Singer H, Muller S, Tixier C, Pillonel L. Triclosan: Occurrence and fate of a widely used biocide in the aquatic environment: field measurements in wastewater treatment plants, surface waters, and lake sediments. Environ Sci Technol, 2002, 36: 4998-5004 
19 Halden RU, Paull DH. Co-occurrence of triclocarban and triclosan in U.S. water resources. Environ Sci Technol, 2005, 39: 1420-1426

20 Ying GG, Yu XY, Kookana RS. Biological degradation of triclocarban and triclosan in a soil under aerobic and anaerobic conditions and comparison with environmental fate modelling. Envir Pollut, 2007, 150: 300-305

21 Guo JH, Li XH, Cao XL, Li Y, Wang XZ, Xu XB. Determination of triclosan, triclocarban and methyl-triclosan in aqueous samples by dispersive liquid-liquid microextraction combined with rapid liquid chromatography. J Chromatogr A, 2009, 1216: 3038-3043

22 Li YY, Wei GH, Hu J, Liu XJ, Zhao XN, Wang XD. Dispersive liquid-liquid microextraction followed by reversed phase-high performance liquid chromatography for the determination of polybrominated diphenyl ethers at trace levels in landfill leachate and environmental water samples. Anal Chim Acta, 2008, 615: 96-103

23 Zhou QX, Bai HH, Xie GH, Xiao JP. Temperature-controlled ionic liquid dispersive liquid phase micro-extraction. J Chromatogr A, 2008, 1177: 43-49

24 Baghdadi M, Shemirani F. In situ solvent formation microextraction based on ionic liquids: A novel sample preparation technique for determination of inorganic species in saline solutions. Anal Chim Acta, 2009, 634: 186-191

25 Erickson BE. Methyl triclosan found in Swiss lakes. Environ Sci Technol, 2002, 36: 228A-230 